\title{
Effect of Amino Acid Additives on Crystal Growth Parameters and Properties of Ammonium Dihydrogen Phosphate Crystals
}

\author{
P.V. Dhanaraj and N.P. Rajesh \\ Centre for Crystal Growth, SSN College of Engineering, \\ Kalavakkam \\ India
}

\section{Introduction}

The isomorphous ammonium dihydrogen phosphate (ADP) and potassium dihydrogen phosphate (KDP) are technologically important crystals grown in large size for various applications. ADP crystal is of more appeal due to its piezo-electric property (Tukubo et al., 1989). Studies on ADP crystals attract interest because of their unique nonlinear optical, dielectric and antiferroelectric properties (Gunning et al., 2001). ADP crystals are widely used as the second, third and fourth harmonic generators for Nd: YAG, Nd: YLF lasers and for electro-optical applications such as Q-switches for Ti: Sapphire, Alexandrite lasers, as well as for acousto-optical applications. ADP crystal has found applications in NLO, electrooptics, transducer devices and as monochromators for X-ray fluorescence analysis.

The room temperature structure of ADP determined by X-ray diffraction analysis was reported by Ueda (1948). Tenzer et al (1958) and Hewat (1973) examined the structure by neutron diffraction analysis. The projection of the structure onto the $b, c$ plane is shown in Figure 1.

ADP differs from KDP by having extra $\mathrm{N}-\mathrm{H}-\mathrm{O}$ hydrogen bonds which connect $\mathrm{PO}_{4}$ tetrahedra with neighbouring $\mathrm{NH}_{4}$ group. Each oxygen atom is connected with another oxygen atom in the neighboring $\mathrm{PO}_{4}$ ion and with a nitrogen atom in a neighbouring $\mathrm{NH}_{4}$ ion by two Kinds of bonds: (O-H-O) and (N-H-O). According to the positional refinements of each atom in ADP by X-ray diffraction study (Srinivasan, 1997), both above and below the phase transition point, each $\mathrm{NH}_{4}$ ion at the potassium position in KDP structure is shifted to the off-center position by forming two shorter and two longer bonds with four $\mathrm{PO}_{4}$ tetrahedra at low temperature phase. When an oxygen is connected with the shorter $\mathrm{N}-\mathrm{H}-\mathrm{O}$ bond, it tends to keep the other proton off in the O-H-O bond and when with the longer $\mathrm{N}-$ $\mathrm{H}-\mathrm{O}$ bond it tends to take the acid proton nearby. Thus the extra hydrogen bonds produce a distorted $\mathrm{NH}_{4}$ ion lattice at low temperature and co-operate with the acid protons in causing proton configurations different from those found at low temperature in KDP (Matsushita et al., 1987). As a representative hydrogen bonded material, ADP has attracted extensive attention in the investigation of hydrogen bonding behaviors in crystal and the relationship between crystal structures and their properties. 


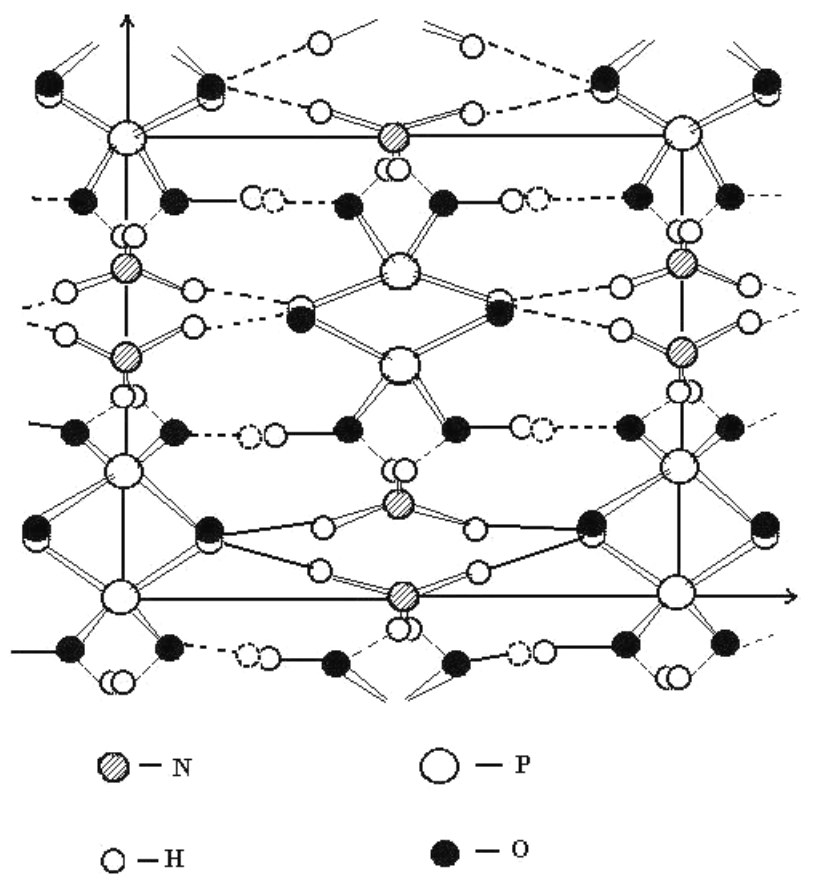

Fig. 1. The (100) projection of ADP structure.

Several researchers have carried out a lot of studies in pure and doped ADP crystals (Zaitseva et al., 2001; Ren et al 2008). In ADP and KDP crystal growth, the metallic cations present in the solutions, especially materials with high valency were considered to strongly affect the growth habit and optical properties of the crystals. The most dangerous impurities which affect the growth habit are trivalent metals $\mathrm{Cr}^{3+}, \mathrm{Fe}^{3+}$ and $\mathrm{Al}^{3+}$ (Alexandru et al., 2003). Even after repeated recrystallization, the presence of small amount of those kinds of impurities in the solution suppresses the crystal quality and growth rate. Here comes the importance of beneficial effects of additives in the crystal growth. An additive can suppress, enhance or stop the growth of crystal completely and its effects depend on the additive concentration, supersaturation, temperature and $\mathrm{pH}$ of the solution. Some dopants are added to suppress the effect of metal ion impurities on ADP and KDP crystals. For example, EDTA and $\mathrm{KCl}$ reduces the effect of metal ion impurities and enhance the metastable zone width and increases the growth rate of the crystals (Rajesh et al., 2000; Podder 2002; Meenakshisundaram et al., 2009). The addition of such kind of dopants does not remove the impurities present in the solution; it just reacts with the metal ions and is making complexes. By making complex, the ions become bigger in size and it is not possible to enter into the growing crystal (Li et al., 2005; Asakuma et al., 2007). Studies have also been made about the effect of additives on growth, habit modification and structure of ADP (Davey et al., 1974; Boukhris et al., 1998). The adsorption of impurities at different sites can cause growth inhibitions, even block the growing surface and in consequence stop the growth process. However, the adsorbed impurities may simultaneously lead to a reduction in the edge free energy, which results in an increase in crystal growth rate (Rak et al., 2005). Several dopants 
help in the growth of ADP crystals at with higher growth rate and enhancement in the various properties of the crystals. The growth promoting effect is observed in the presence of organic additives (Kern et al., 1992; Bhagavannarayana et al., 2006) as well as inorganic additives (Shantha et al., 1997; Podder et al, 2001).

Amino acid family crystals exhibit excellent nonlinear optical and electro-optical properties. Reports are available in literature on the doping of amino acids in technologically important crystals and the enhancement of the material properties like nonlinear optical and ferroelectric properties. For example, enhancement of Second Harmonic Generation (SHG) efficiency has been reported in L-arginine doped KDP crystals (Parikh et al., 2007). Kumaresan et al (2008) reported the doping of amino acids (L-glutamic acid, L-histidine, Lvaline) with KDP and studied its properties. The effects on various properties of Ltheronine, DL-theronine and L-methionine admixtured Triglycine Sulfate (TGS) crystals were studied and the authors reported that the admixtured TGS crystal has different properties compared to pure TGS crystal (Meera et al., 2004). Batra et al (2005) investigated the growth kinetics of KDP and TGS crystals doped with L-arginine phosphate monohydrate. The addition of L-arginine decreases the value of dielectric constant of KDP crystals (Meena et al., 2008).

In the light of research work being done on ADP crystals, to improve their growth and other characteristics, it was thought interesting and worthwhile to investigate the effects of amino acid materials L-arginine monohydrochloride $\left(\mathrm{C}_{6} \mathrm{H}_{15} \mathrm{~N}_{4} \mathrm{O}_{2} \mathrm{Cl}\right)$ and L-alanine $\left(\mathrm{C}_{3} \mathrm{H}_{7} \mathrm{NO}_{2}\right)$ on nucleation studies, growth and properties of ADP crystals for both academic and industrial uses. The reason for choosing the dopants is that L-arginine monohydrochloride and Lalanine are efficient NLO materials under the amino acid category. Monaco et al (1987) discovered NLO material L-arginine monohydrochloride, which belongs to space group P2 1 of monoclinic system with two molecules in the asymmetric unit. L-alanine crystallizes in orthorhombic system with noncentrosymmetric space group P $2{ }_{1} 2_{1} 2_{1}$ (Razzetti et al., 2002).

\section{Experimental studies}

\subsection{Determination of solubility and metastable zone width}

Metastable zone width is an essential parameter for the growth of large size crystals from a solution, since it is the direct measure of the stability of the solution in its supersaturated region. Metastable zone width is an experimentally measurable quantity which depends on number of factors, such as stirring rate, cooling rate of the solution and presence of additional impurities (Nyvlt et al., 1970; Sangwal 1989; Zaitseva et al., 1995). Ammonium dihydrogen phosphate, L-arginine monohydrochloride (LAHCl) and L-alanine of GR grade from Merck and Millipore water of resistivity $18.2 \mathrm{M} \Omega \mathrm{cm}$ were used for all studies. No further purification was done. The solubility was determined gravimetrically for pure ADP and ADP doped with small amount (5 mol\%) of LAHCl and L-alanine separately as additives. Polythermal method (Nyvlt et al 1970) was adopted for the metastable zonewidth studies of pure and doped ADP solutions. The ADP solution $(600 \mathrm{ml})$ saturated at $30{ }^{\circ} \mathrm{C}$ was prepared according to the solubility diagram with continuous stirring using a magnetic stirrer and the solutions were filtered. Three similar beakers with $200 \mathrm{ml}$ solution each were used; the first beaker contained pure ADP solution whereas the second and the third beakers contained $5 \mathrm{~mol} \% \mathrm{LAHCl}$ and $5 \mathrm{~mol} \% \mathrm{~L}$-alanine doped ADP solutions respectively. Then pure and doped ADP solutions were kept in a Constant Temperature Bath (CTB) with cooling facility. After stirring for $6 \mathrm{~h}$, the solution was slowly cooled at a desired cooling rate 
of $4{ }^{\circ} \mathrm{C} / \mathrm{h}$, until the first crystal appeared. The experiments were repeated for different saturation temperatures $(30-50){ }^{\circ} \mathrm{C}$ with the interval of $5{ }^{\circ} \mathrm{C}$ and the corresponding metastable zonewidths were measured. Several nucleation runs (7-9 times) were carried out under controlled conditions and reproducible results with the accuracy of $\pm 0.25 \%$ were obtained. The metastability limit of $\mathrm{LAHCl}$ added solution and L-alanine added solution is shown in Figure 2 in comparison with the pure system.

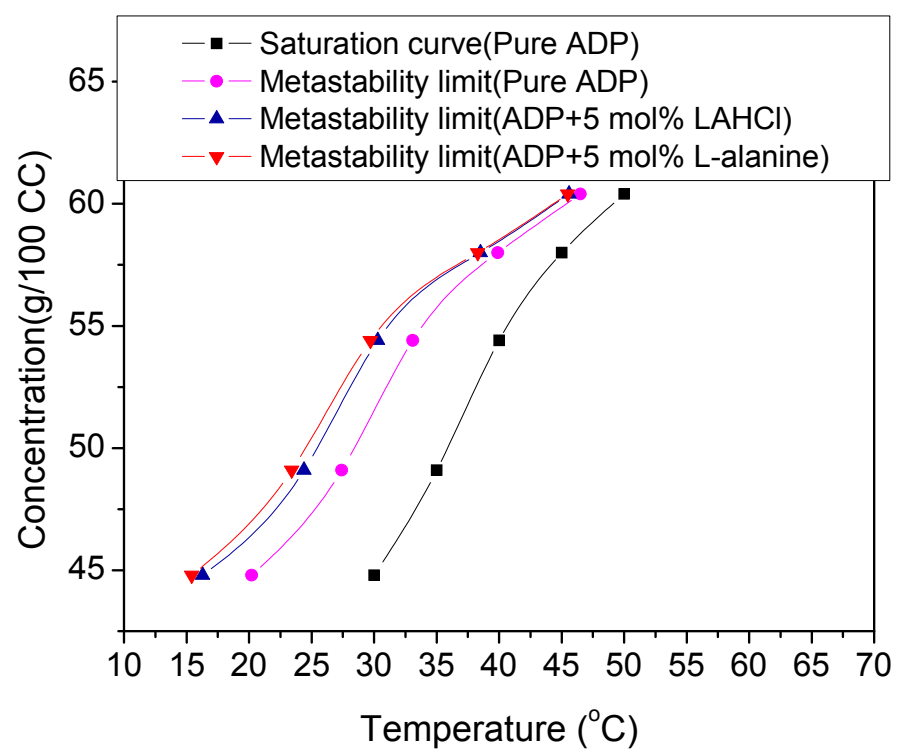

Fig. 2. Saturation and metastability limit curves of pure, $\mathrm{LAHCl}$ and L-alanine added ADP solutions.

It is obvious from the figure that the zone widths for all the solutions decrease as the temperature increases. At the same time, the addition of dopants enhances the metastable zonewidth of ADP solutions for all the temperatures studied in this work, and makes the ADP solution more stable. During the experiment, the number of tiny crystals formed by spontaneous nucleation was appreciably reduced in the case of the doped solutions compared with the pure one. Among the two additives, the additive L-alanine enhances the metastable zonewidth of ADP than the other additive $\mathrm{LAHCl}$ especially at lower temperatures. The addition of these amino acid additives can make ADP solution more stable.

\subsection{Determination of induction period}

The induction period, a measure of the nucleation rate was determined experimentally for ADP solutions with and without the presence of additives at different supersaturations by means of isothermal method (Zaitseva et al., 1995). The "direct vision method" by naked eye is used for measuring induction period. Aqueous solutions of various supersaturated concentrations were prepared. Supersaturation was obtained by natural cooling. Supersaturated solutions of equal volume $(100 \mathrm{ml})$ were taken in the cells at a higher 
temperature. As the temperature of the cell reached the experimental temperature $\left(35{ }^{\circ} \mathrm{C}\right)$, the time was noted. Once the nucleation occurred, it grew quickly and a bright sparkling particle was seen. The time of observation of the sparkling particle in the cell from the time at which the solution reaches the experimental temperature of nucleation (temperature of beginning of nucleation) gives the induction period of nucleation. The effect of heterogeneous nucleation due to scratching on the inner wall of the nucleation cell was reduced by choosing a glass beaker without scratches. Experiments were performed at selected degrees of supersaturation (c/ $\left.\mathrm{c}_{\mathrm{o}}\right)$, viz., 1.25, 1.275, 1.3, c being the mole fraction of solute in supersaturated solution and $c_{o}$ is the equilibrium concentration. Several nucleation runs (5-7 times) were carried out under controlled conditions and reproducible results with the accuracy of $\pm 0.25 \%$ were obtained. The experimental results of induction period for pure and doped ADP solutions are presented in Figure 3.

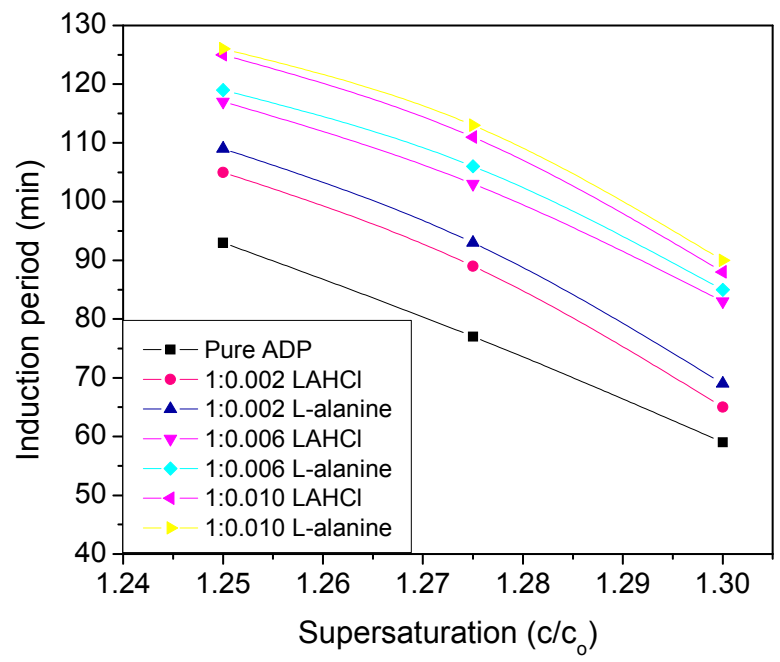

Fig. 3. Values of induction period against supersaturation.

Considering the principles of homogeneous and heterogeneous nucleation theories, the free energy of formation of a nucleus under heterogeneous nucleation is less than that of a homogeneous condition (Sangwal 1996; Srinivasan et al 1999). Considering the additive added system it can be noticed that the induction period of doped ADP is higher than that of pure and it increases with the increase in the additive concentration. Among the additives, L-alanine has a longer higher induction period than $\mathrm{LAHCl}$ at every concentration. The presence of additives in the system affects the nucleation behavior very considerably. This may be due to the suppression of chemical activity of the metal ions present in the ADP solution (Mullin 1993).

\subsection{Growth rate measurements}

The growth rate of a crystal is known to be changed by traces of certain impurities or additives. In this work, the influence of the additives on the growth rate of ADP crystals is 
determined by the weighing method put forwarded by Kubota et al (1995). By this method, the growth rate of a crystal is defined as

$$
\mathrm{G}_{\mathrm{g}}=\left(\mathrm{m}-\mathrm{m}_{\mathrm{o}}\right) / \mathrm{m}_{\mathrm{o}} \Delta \theta
$$

where $m_{o}$ is the initial mass of the crystal $(\mathrm{kg}), \mathrm{m}$ is the final mass of the crystal $(\mathrm{kg})$, and $\Delta \theta$ is the growth time. Here growth time is taken as $1 \mathrm{~h}$. A single crystal with a size of $5-10 \mathrm{~mm}$ was used as the seed for the experiment. The seed crystal (of mass $m_{0}$ ) was suspended in the solution in $500 \mathrm{ml}$ glass vessel (working volume: $400 \mathrm{ml}$ ) for $1 \mathrm{~h}(\Delta \theta)$ for growth. The solution was continuously stirred throughout the process. Supercooling was varied from 2 to $10^{\circ} \mathrm{C}$ by changing the growth temperature. The same procedure is done for pure and doped ADP crystals. Figure 4 shows the growth rates of pure and doped ADP crystals.

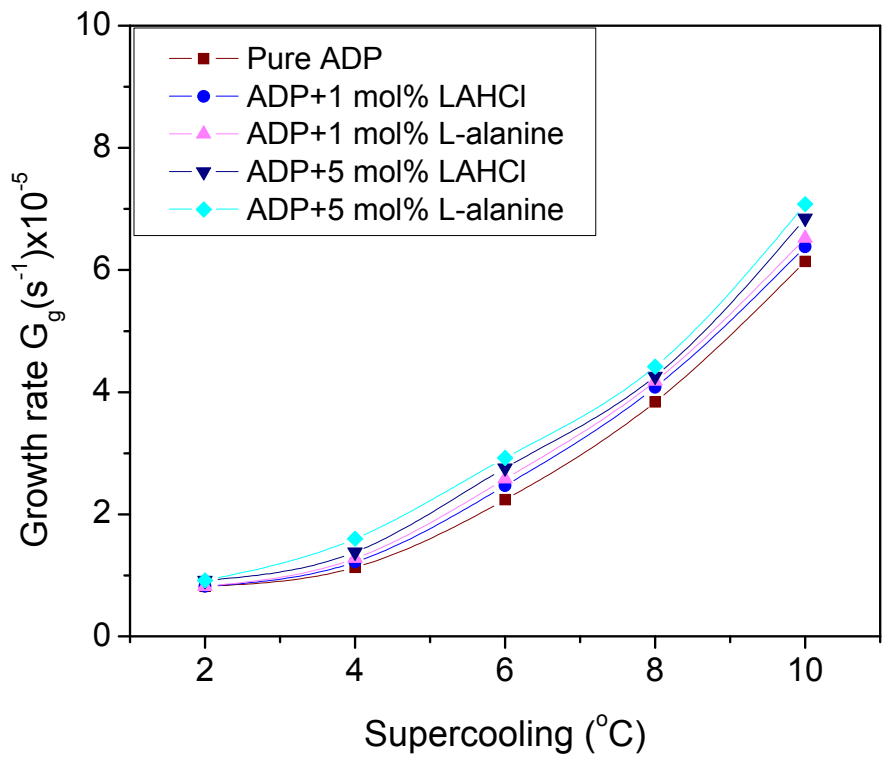

Fig. 4. Variation of mass growth rates for pure and doped ADP crystals.

The presence of additives is found to have an influence on the growth rate. The role of additives during the growth process could be visualized as follows. The additives LAHCl and L-alanine have higher solubility than that of the crystallizing substance (ADP). The additives might have changed the thermodynamic parameters, i.e. the surface concentration of the growth species and the surface energy. An increase in solubility by the addition of $\mathrm{LAHCl}$ and L-alanine may lead to decrease in the surface energy, which consequently decreases the rates of layer displacement that cause an increase in the growth rate (Sangwal 1996).

\subsection{Crystal growth}

In the present work, ADP crystals doped with $5 \mathrm{~mol} \% \mathrm{LAHCl}$ and L-alanine separately were grown from aqueous solution with a simple apparatus that can be applied in certain 
forced convection configurations to maintain a higher homogeneity of the solution. This apparatus consists of seed rotation controller coupled with a stepper motor, which is controlled by using a microcontroller based drive. This controller rotates the seed holder in the crystallizer. The seed crystal is mounted on the center of the platform made up of acrylic material and is fixed into the crystallizer. The seed mount platform stirs the solution very well and makes the solution more stable, which results in better crystal quality. The schematic diagram of the seed rotation controller designed for low temperature solution growth method is shown in Figure 5. The uniform rotation of the seed is required to avoid stagnant regions or re-circulating flows, otherwise inclusions in the crystals will be formed due to inhomogeneous supersaturation in the solution (Fu et al., 2000).

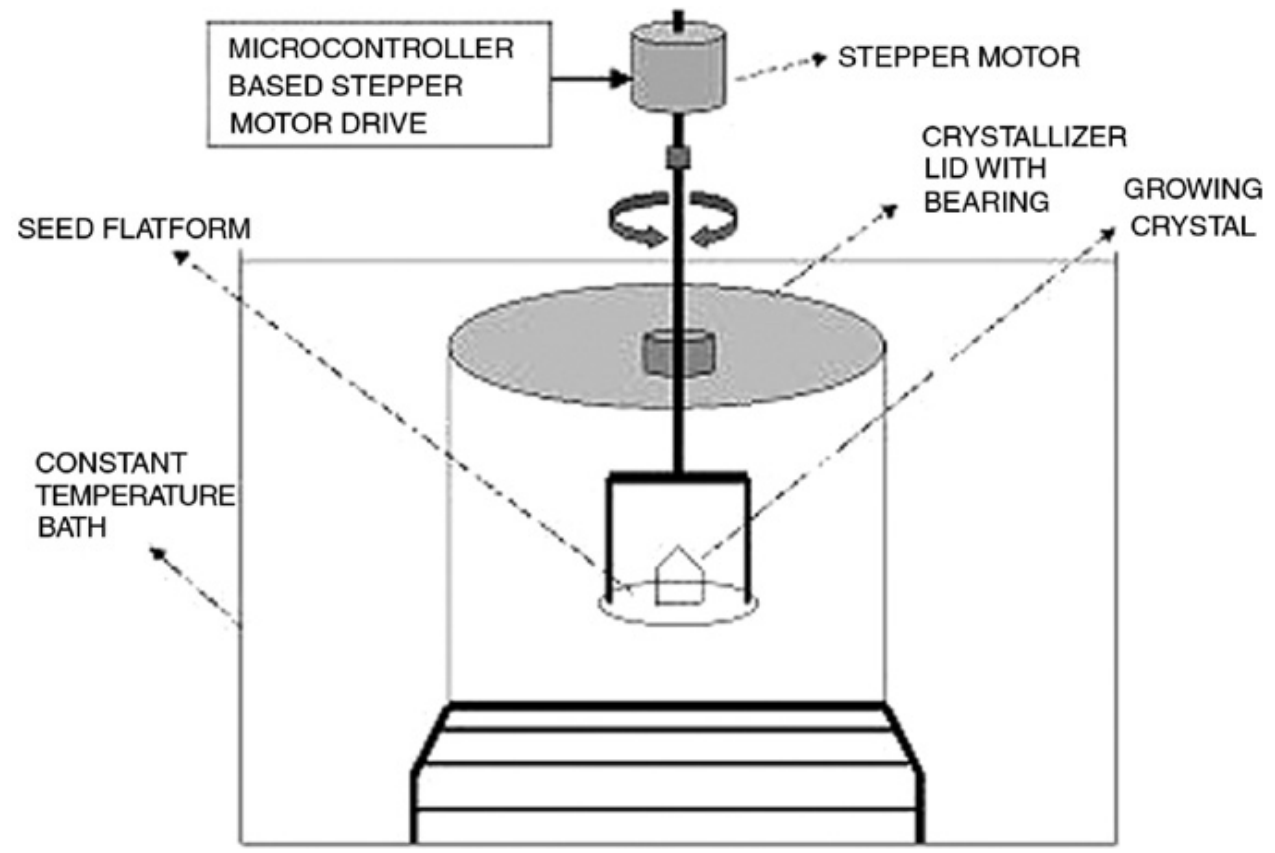

Fig. 5. Schematic diagram of the seed rotation controller.

The crystal growth was carried out in a $5000 \mathrm{ml}$ standard crystallizer used for conventional crystal growth by using the method of temperature reduction. The temperature of solution in the crystallizer was controlled using a CTB and the temperature fluctuations are less than $0.01^{\circ} \mathrm{C}$. The saturation temperature was $50^{\circ} \mathrm{C}$. The solution was filtered by filtration pump and Whatman filter paper of pore size $11 \mu \mathrm{m}$ under slight pressure in a closed system to remove extraneous solid and colloidal particles, which may act as the centers of spontaneous nucleation during growth. Then the solutions were overheated at $70{ }^{\circ} \mathrm{C}$ for 24 h. This duration of overheating was found to be effective to destroy the molecule clusters existing in the solution and to make the solution stable against spontaneous nucleation 
under a high supersaturation (Zaitseva et al., 1995; Nakatsuka et al., 1997). Then the temperature of the solution was reduced to $3-5{ }^{\circ} \mathrm{C}$ higher than saturation point $\left(50{ }^{\circ} \mathrm{C}\right)$ at $1 \mathrm{oC} / \mathrm{h}$. After that temperature was reduced to the saturation point at $1 \mathrm{oC} /$ day and the seed crystal was mounted on the platform. The rotation rate of the platform was $40 \mathrm{rpm}$. From the saturation point, the temperature was decreased at $0.1{ }^{\circ} \mathrm{C} /$ day at the beginning of the growth. As the growth progressed, the temperature lowering rate was increased up to 1 ${ }^{\circ} \mathrm{C} /$ day. After the growth period of 30 days, crystals were harvested. The as-grown crystals are shown in Figure 6. In the figure, (a) is ADP doped with L-Alanine and (b) is ADP doped with LAHCl.

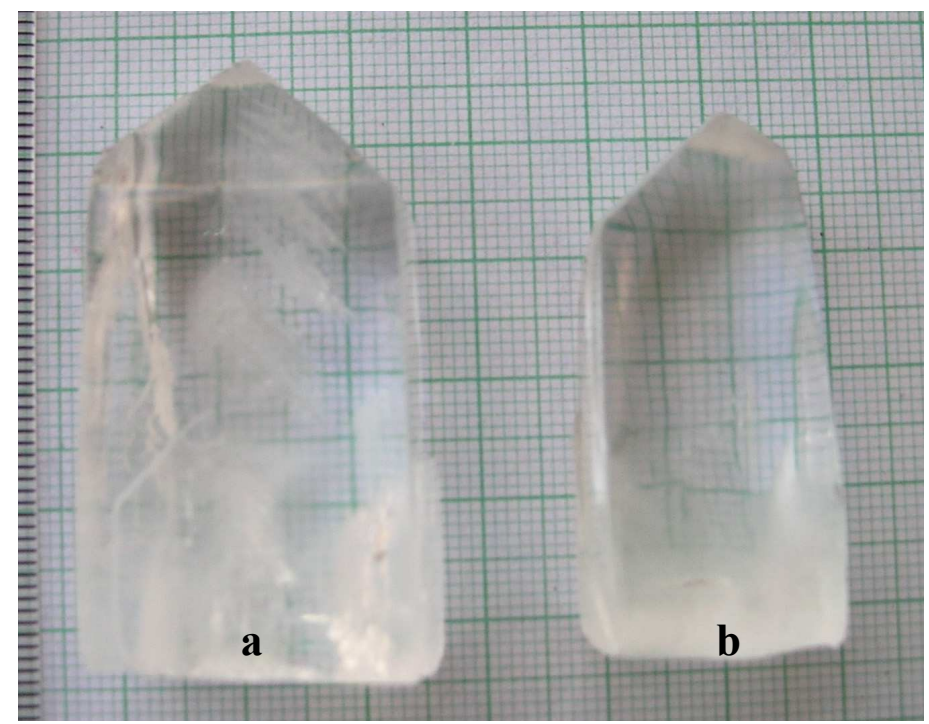

Fig. 6. Photograph of L-alanine doped ADP crystal and LAHCl doped ADP crystal

For various characterization techniques, pure and doped (in concentrations 1 and $5 \mathrm{~mol} \%$ ) ADP crystals were grown by slow cooling method under identical conditions.

\section{Analysis of physicochemical studies}

\subsection{Powder XRD studies}

The powder X-ray diffraction is useful for confirming the identity of a solid material and determining crystallinity and phase purity. Grown crystals were ground using an agate mortar and pestle in order to determine the crystal phases by X-ray diffraction. Powder Xray diffraction study was carried out by employing SEIFERT, 2002 (DLX model) diffractometer with $\mathrm{CuK}_{\alpha}(\lambda=1.5405 \AA)$ radiation using a tube voltage and current of $40 \mathrm{kV}$ and $30 \mathrm{~mA}$ respectively. Figure 7 shows X-ray powder diffraction patterns of ADP doped with $\mathrm{LAHCl}(5 \mathrm{~mol} \%$ ) and ADP doped with L-alanine $(5 \mathrm{~mol} \%$ ) compared with that of pure ADP crystal. X-ray powder diffraction patterns of pure ADP and doped ADP crystals are identical. As seen in the figure, no additional peaks are present in the XRD spectra of doped ADP crystals, showing the absence of any additional phases due to doping. 


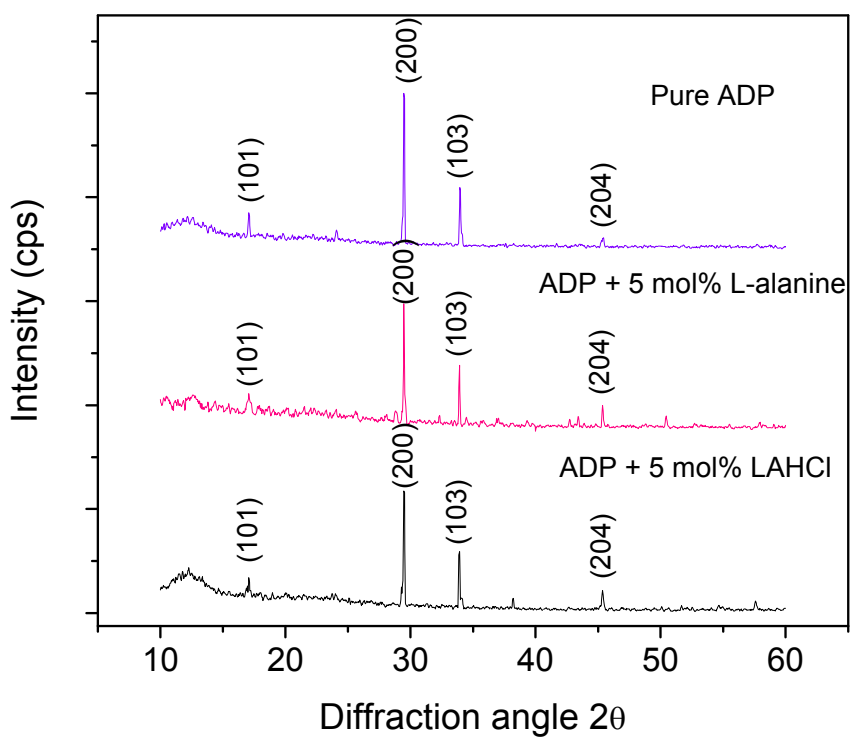

Fig. 7. X-ray powder diffraction patterns of ADP crystals.

\subsection{High-resolution x-ray diffraction (HRXRD) analysis}

The crystalline perfection of the grown single crystals was characterized by HRXRD analysis by employing a multicrystal X-ray diffractometer designed and developed at National Physical Laboratory (Lal et al., 1989). Figure 8 shows the schematic diagram of the multicrystal $X$-ray diffractometer. The divergence of the $X$-ray beam emerging from a fine focus X-ray tube (Philips X-ray Generator; $0.4 \mathrm{~mm} \times 8 \mathrm{~mm}$; $2 \mathrm{kWMo}$ ) is first reduced by a long collimator fitted with a pair of fine slit assemblies. This collimated beam is diffracted twice by two Bonse-Hart (Bonse et al., 1965) type of monochromator crystals and the thus diffracted beam contains well resolved MoK $\alpha_{1}$ and MoK $\alpha_{2}$ components. The MoK $\alpha_{1}$ beam is isolated with the help of fine slit arrangement and allowed to further diffract from a third (111) Si monochromator crystal set in dispersive geometry $(+,-,-)$. Due to dispersive configuration, though the lattice constant of the monochromator crystal and the specimen are different, the dispersion broadening in the diffraction curve of the specimen does not arise. Such an arrangement disperses the divergent part of the $\mathrm{MoKa}_{1}$ beam away from the Bragg diffraction peak and thereby gives a good collimated and monochromatic MoK $\alpha_{1}$ beam at the Bragg diffraction angle, which is used as incident or exploring beam for the specimen crystal. The dispersion phenomenon is well described by comparing the diffraction curves recorded in dispersive $(+,-,-)$ and non-dispersive $(+,-,+)$ configurations (Bhagavannarayana 1994). This arrangement improves the spectral purity $\left(\Delta \lambda / \lambda<<10^{-5}\right)$ of the MoK $\alpha_{1}$ beam. The divergence of the exploring beam in the horizontal plane (plane of diffraction) was estimated to be $<<3$ arc $s$. The specimen occupies the fourth crystal stage in symmetrical Bragg geometry for diffraction in $(+,-,-,+)$ configuration. The specimen can be rotated about a vertical axis, which is perpendicular to the plane of diffraction, with minimum angular interval of 0.4 arc s. The diffracted intensity is measured by using an in- 
house developed scintillation counter. To provide two-theta $\left(2 \theta_{\mathrm{B}}\right)$ angular rotation to the detector (scintillation counter) corresponding to the Bragg diffraction angle $\left(\theta_{\mathrm{B}}\right)$, it is coupled to the radial arm of the goniometer of the specimen stage. The rocking or diffraction curves were recorded by changing the glancing angle (angle between the incident $X$-ray beam and the surface of the specimen) around the Bragg diffraction peak position $\theta_{\mathrm{B}}$ (taken as zero for the sake of convenience) starting from a suitable arbitrary glancing angle. The detector was kept at the same angular position $2 \theta_{\mathrm{B}}$ with wide opening for its slit, the so-called $\omega$ scan.

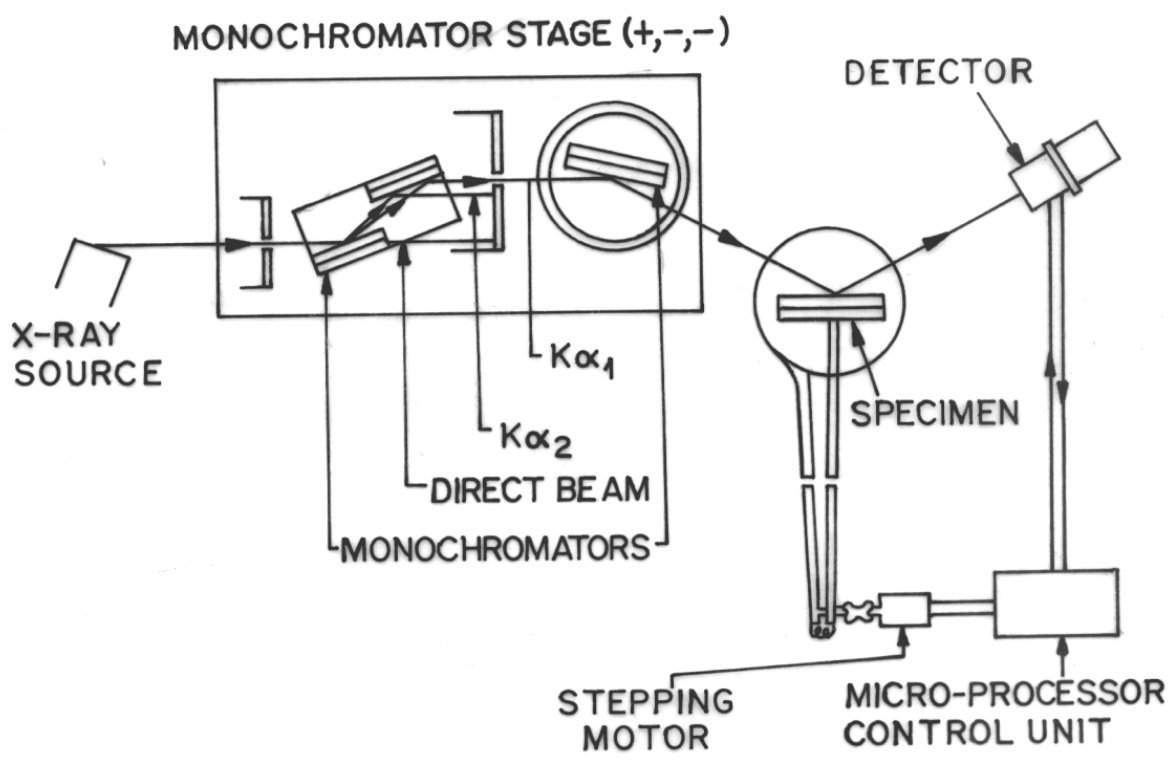

Fig. 8. Schematic line diagram of multicrystal X-ray diffractometer designed, developed and fabricated at National Physical Laboratory

Before recording the diffraction curve to remove the non-crystallized solute atoms remained on the surface of the crystal and also to ensure the surface planarity, the specimen was first lapped and chemically etched in a non preferential etchant of water and acetone mixture in $1: 2$ ratio.

Figure 9 shows the high-resolution diffraction curve (DC) recorded for LAHCl doped (5 mol\%) ADP specimen and Figure 10 shows the DC recorded for L-alanine doped (5 mol\%) ADP specimen using (200) diffracting planes in symmetrical Bragg geometry by employing the multicrystal X-ray diffractometer with $M o K \alpha_{1}$ radiation. The curves are very sharp having full width at half maximum (FWHM) of 8 arc s for LAHCl doped ADP and 5 arc $s$ for L-alanine doped ADP crystals as expected for nearly perfect crystals from the plane wave dynamical theory of X-ray diffraction (Batterman et al., 1964). The absence of additional peaks and the very sharp DC shows that the crystalline perfection of the specimen crystals is extremely good without having any internal structural grain boundaries and mosaic nature. The high reflectivity $(\approx 50 \%$ in LAHCl doped and $\approx 60 \%$ in L-alanine doped) and the very small value of FWHM indicate that even the unavoidable point defects like self interstitials 
and vacancy defects (Lal et al., 1989) are also extremely low. However, the quality of L-alanine doped ADP specimen is better than that of $\mathrm{LAHCl}$ doped specimen.

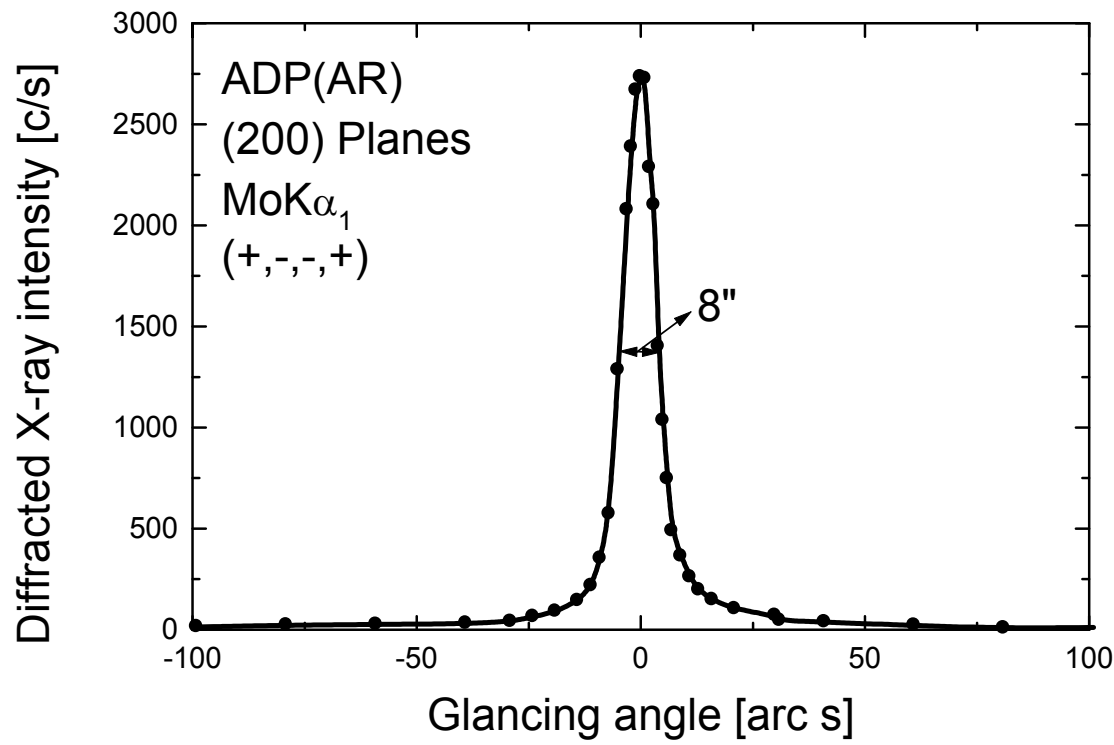

Fig. 9. Diffraction curve recorded for $\mathrm{LAHCl}$ doped ADP single crystal using (200) diffracting planes.

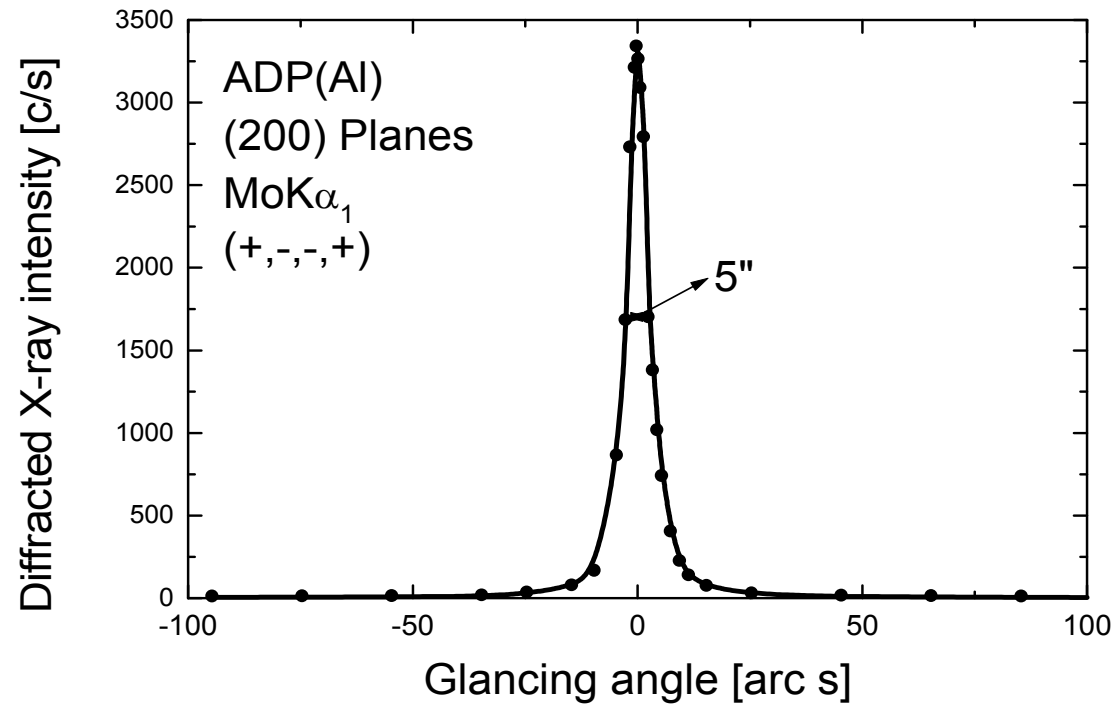

Fig. 10. Diffraction curve recorded for L-alanine doped ADP single crystal using (200) diffracting planes. 


\subsection{FTIR spectral analysis}

The influence of additives used in this work on the vibration frequencies of functional groups of pure ADP crystal has been identified by FTIR spectroscopy. The FTIR spectra were recorded in the region $400-4000 \mathrm{~cm}^{-1}$ using a Perkin-Elmer FTIR Spectrum RXI spectrometer by $\mathrm{KBr}$ pellet technique. Figure 11 shows the FTIR spectra of the pure ADP, ADP doped with LAHCl ( $1 \mathrm{~mol} \%)$ and ADP doped with L-alanine ( $1 \mathrm{~mol} \%)$. The broad band in the high energy region is due to $\mathrm{O}-\mathrm{H}$ vibrations of water, $\mathrm{P}-\mathrm{O}-\mathrm{H}$ group and $\mathrm{N}-\mathrm{H}$ vibrations of ammonium (Rajesh et al., 2009). The broadness is due to the hydrogen bonding interaction with adjacent molecules (Rani et al., 2011). The peak at $2370 \mathrm{~cm}^{-1}$ is due to the combination band of vibrations occurring at 1293 and $1290 \mathrm{~cm}^{-1}$. The bending vibrations of water give the peak at $1646 \mathrm{~cm}^{-1}$. The peak at $1402 \mathrm{~cm}^{-1}$ is due to bending vibrations of ammonium (Rani et al., 2011). The P-O-H vibrations give the peaks at 1090 and $930 \mathrm{~cm}^{-1}$. The $\mathrm{PO}_{4}$ vibrations give their peaks at 544 and $470 \mathrm{~cm}^{-1}$.

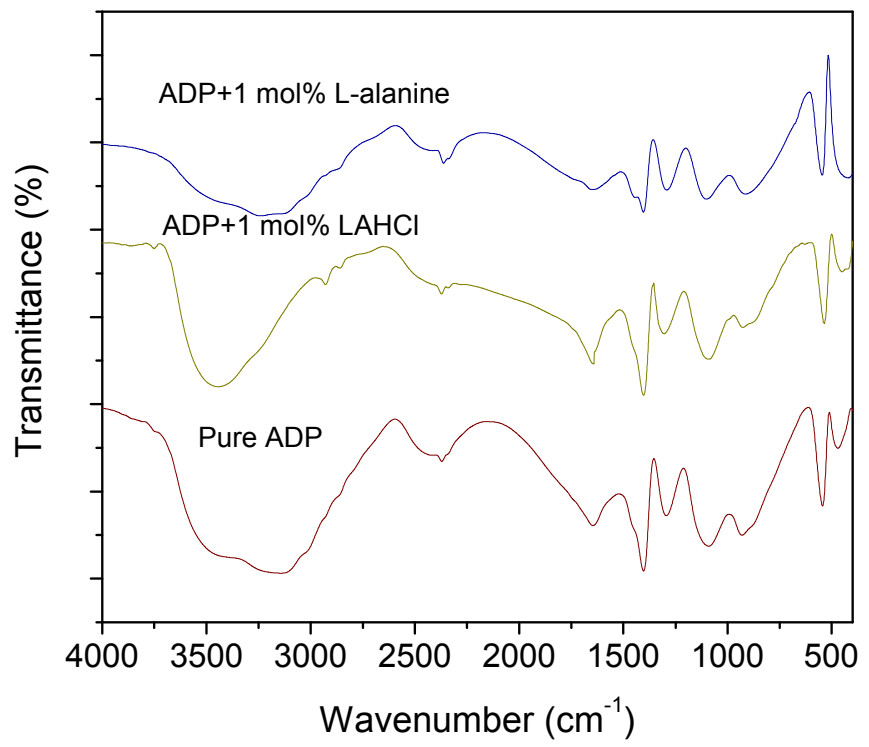

Fig. 11. FTIR spectra of pure ADP, ADP doped with $\mathrm{LAHCl}$ and ADP doped with L-alanine.

In the spectrum of ADP doped with $\mathrm{LAHCl}$, the intense band appearing at $3442 \mathrm{~cm}^{-1}$ includes $\mathrm{O}-\mathrm{H}$ vibrations and $\mathrm{N}-\mathrm{H}$ vibrations of ammonium and amino acid. Although this spectrum carries similar features as that of ADP, there is a distinct evidence for the presence of $\mathrm{LAHCl}$ in the lattice of ADP. The peaks appearing at $2928 \mathrm{~cm}^{-1}$ and about 2890 $\mathrm{cm}^{-1}$ are due to $\mathrm{CH}_{2}$ vibrations of $\mathrm{LAHCl}$. In addition, shift in the peak positions of $\mathrm{P}-\mathrm{O}-\mathrm{H}$ and $\mathrm{PO}_{4}$ vibrations compared to ADP established the presence of the additive in the lattice of ADP. In the spectrum of ADP with L-alanine also, there is a significant shift in the peak positions. For example, the $\mathrm{PO}_{4}$ vibration of the parent is shifted from 470 to $419 \mathrm{~cm}^{-1}$. Similarly the P-O-H vibrations at 1090 and $930 \mathrm{~cm}^{-1}$ of the parent are shifted to 1101 and $913 \mathrm{~cm}^{-1}$. Such a shift establishes the presence of L-alanine in the lattice of ADP. As the vibrations of L-alanine are not clearly resolved from the spectrum of the parent, it might be in a trace amount below the deductibility limit. There is a slight evidence of $\mathrm{CH}_{2}$ 
vibrations of L-alanine just below $3000 \mathrm{~cm}^{-1}$. All these support the presence of L-alanine in the lattice of ADP.

\subsection{Dielectric studies}

The dielectric constant is one of the basic electrical properties of solids. Dielectric properties are correlated with the electro-optic property of the crystals (Aithal et al., 1997). The capacitance $\left(\mathrm{C}_{\text {crys }}\right)$ and dielectric loss $(\tan \delta)$ of pure and doped ADP crystals were measured using the conventional parallel plate capacitor method for temperatures from 313 to $423 \mathrm{~K}$ with frequency (f) of $1 \mathrm{kHz}$. Good quality transparent crystals of size $7 \times 7 \times 2 \mathrm{~mm}^{3}$ were used for the measurements. The dimensions of the samples were determined using a traveling microscope $(\mathrm{LC}=0.001 \mathrm{~cm})$. Samples were coated with good quality graphite in order to obtain a good ohmic contact. The measurements were done on $\mathrm{a}-\mathrm{b}$ directions of the crystals. The samples were annealed up to $423 \mathrm{~K}$ to remove water molecules if present. The observations were made while cooling the sample and the air capacitance $\left(\mathrm{C}_{\mathrm{air}}\right)$ was also measured. Several trials of experiments were conducted.

The dielectric constant of the crystal was calculated using the relation

$$
\varepsilon_{r}=\frac{C_{c r y s}}{C_{\text {air }}}
$$

As the crystal area was smaller than the plate area of the cell, parallel capacitance of the portion of the cell not filled with the crystal was taken into account and, consequently, the above equation becomes

$$
\varepsilon_{r}=\left(\frac{C_{c r y s}-C_{a i r}\left(1-\frac{A_{c r y s}}{A_{\text {air }}}\right)}{C_{\text {air }}}\right)\left(\frac{A_{\text {air }}}{A_{c r y s}}\right)
$$

where $A_{\text {crys }}$ is the area of the crystal touching the electrode and $A_{\text {air }}$ is the area of the electrode.

Figure 12 shows the temperature dependence of dielectric constants of pure and LAHCl doped ( 1 and $5 \mathrm{~mol} \%)$ ADP crystals. Temperature dependence of dielectric constants of pure and L-alanine doped ( 1 and $5 \mathrm{~mol} \%$ ) ADP crystals are depicted in Figure 13.

It is observed from the figures that the dielectric constant increases with increase in temperature. This is normal dielectric behaviour of an antiferroelectric ADP crystal. In the present study, it has been observed that the LAHCl and L-alanine doped ADP crystals have lower $\varepsilon_{\mathrm{r}}$ values compared to pure. Among these, $5 \mathrm{~mol} \%$ doped crystals have lower $\varepsilon_{\mathrm{r}}$ values than $1 \mathrm{~mol} \%$ doped ones. Suitable dopants added in suitable concentrations can reduce the $\varepsilon_{\mathrm{r}}$ value to a lower one as observed in the case of KDP single crystals added with urea (Goma et al., 2006). Thus, in effect, the present study indicates that $\mathrm{LAHCl}$ and L-alanine doped ADP crystals are not only potential NLO materials but also low $\varepsilon_{\mathrm{r}}$ value dielectric materials, which will be useful for microelectronic industries and electro-optic modulators. The dielectric loss of the grown crystals for various temperatures at the frequency $(1 \mathrm{kHz})$ is shown in Figures 14 and 15. It is observed that the dielectric loss increases with increase in temperature for the crystals. It reveals that doped crystals have lower dielectric loss values compared to pure crystals. 


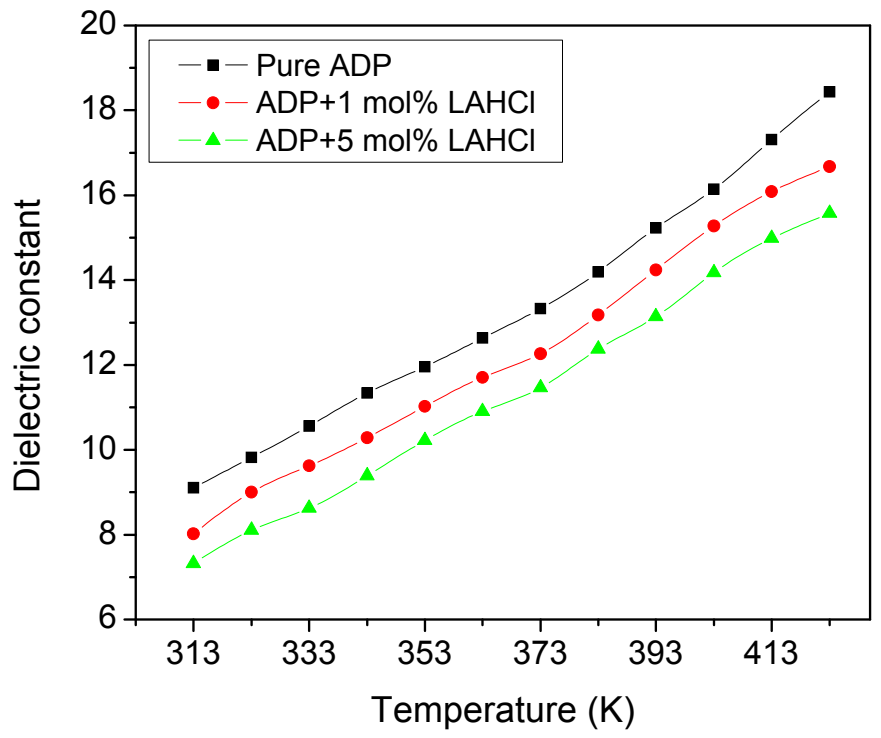

Fig. 12. Variation of dielectric constant with temperature for pure and LAHCl doped ADP crystals.

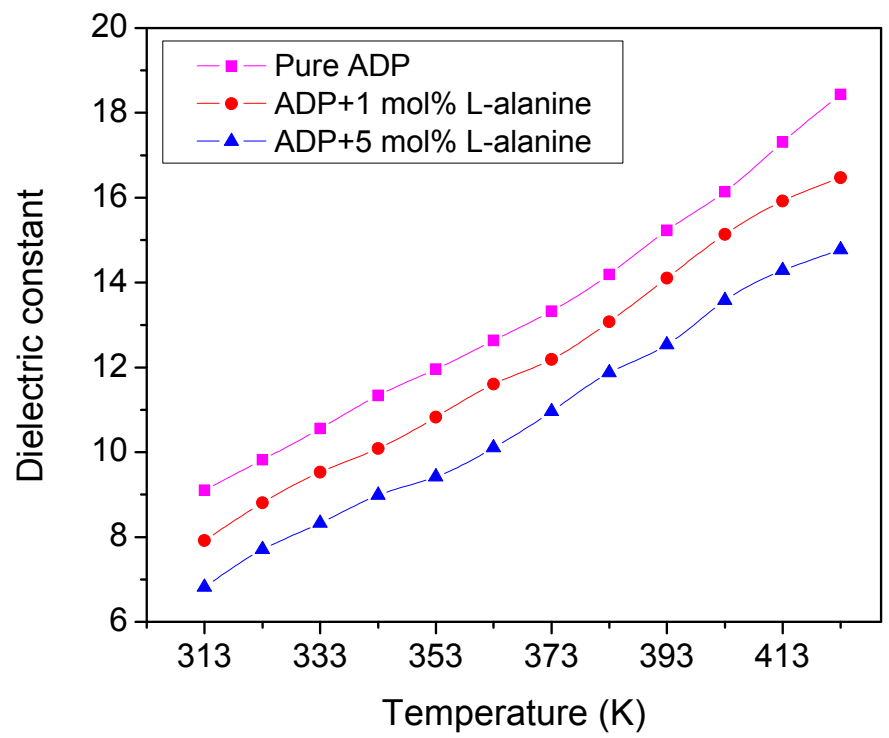

Fig. 13. Variation of dielectric constant with temperature for pure and L-alanine doped ADP crystals. 


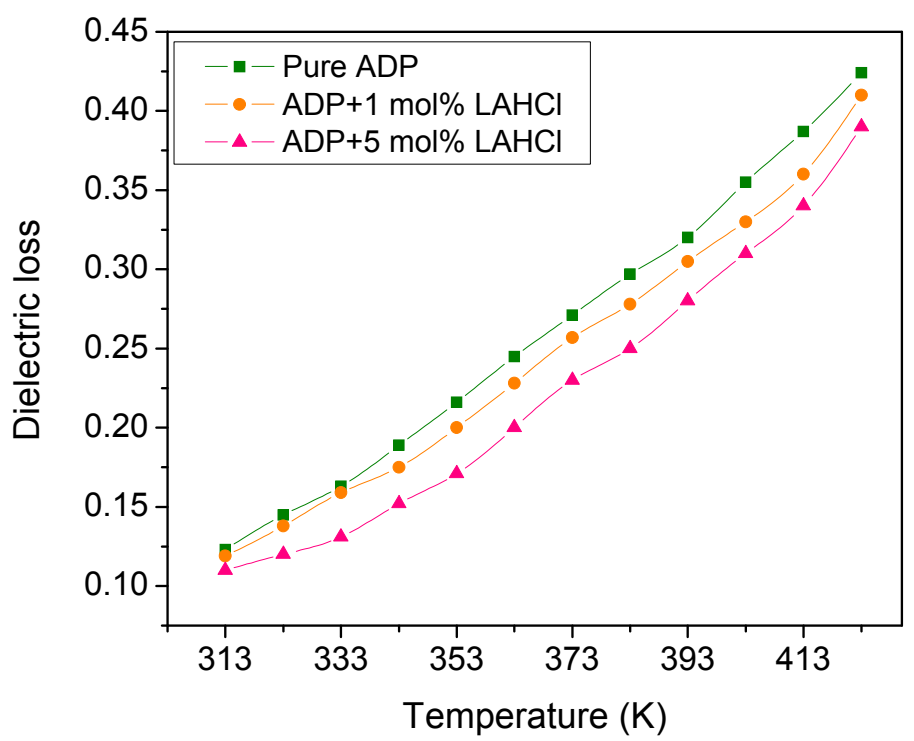

Fig. 14. Variation of dielectric loss with temperature for pure and LAHCl doped ADP crystals.

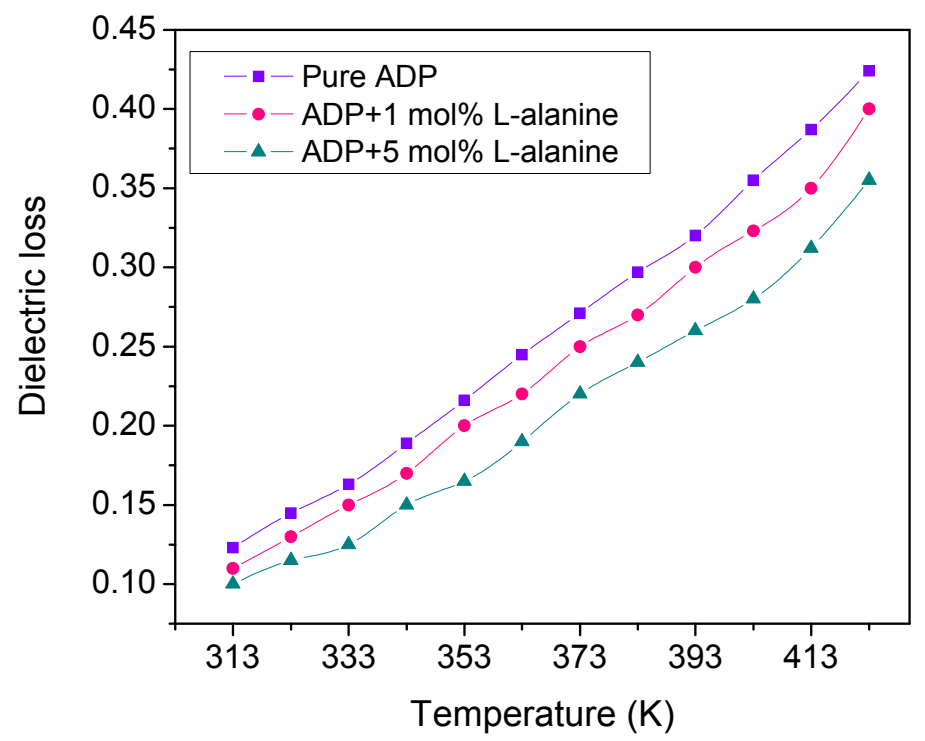

Fig. 15. Variation of dielectric loss with temperature for pure and L-alanine doped ADP crystals. 


\subsection{Optical transmission studies}

Optical transmission spectra were recorded for the samples obtained from pure as well as from doped crystals grown by the slow cooling method. The spectra were recorded in the wavelength region 200-1100 nm using Lambda 35 spectrophotometer. Crystal plates with 2 mm thickness were used for the study. The reported value of the optical transparency for ADP is from 184 to $1500 \mathrm{~nm}$ (Dmitriev et al., 1991). The UV-vis-NIR spectra recorded for pure and doped ADP crystals are shown in Figure 16. It is clear from the figure that the crystals have sufficient transmission (pure ADP has 70\% whereas $\mathrm{LAHCl}$ and L-alanine doped ADP have $78 \%$ and $82 \%$ respectively) in the entire visible and IR region. The optical transparency of the ADP crystal is increased by the addition of LAHCl and L-alanine. The addition of the amino acid dopants in the optimum conditions to the solution is found to suppress the inclusions and improve the quality of the crystal with higher transparency.

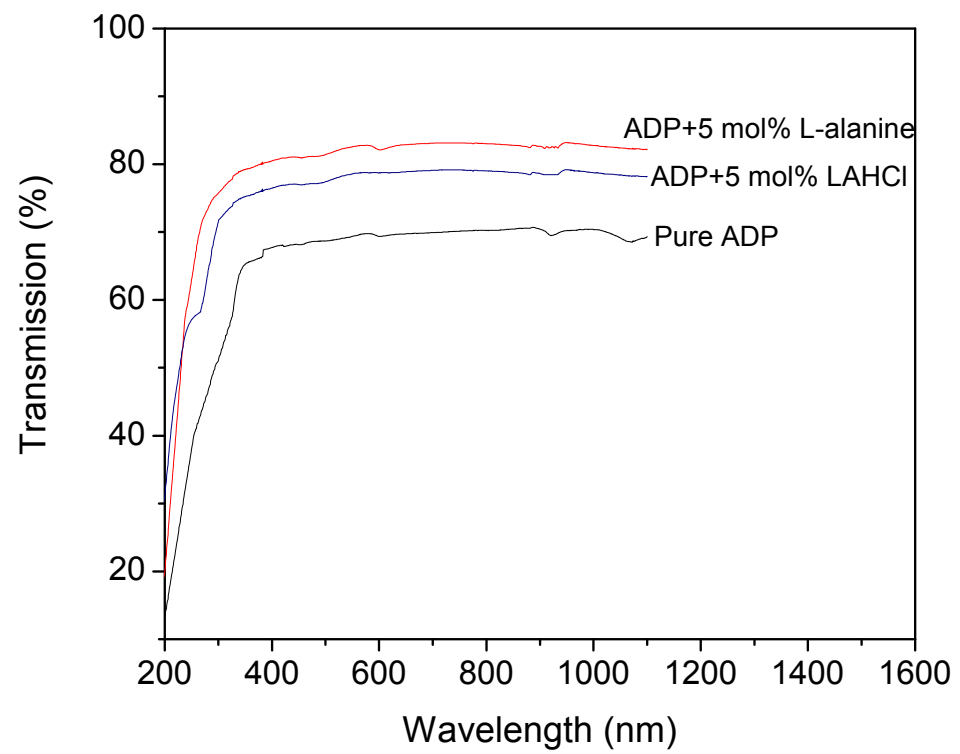

Fig. 16. Transmission spectra of pure and doped ADP crystals.

\subsection{NLO property}

Kurtz and Perry (1968) proposed a powder second harmonic generation method for comprehensive analysis of the second order nonlinearity. This is an important method for characterizing the materials before going through the long and tedious process of growing large optical quality crystals. To determine the SHG conversion efficiency of doped crystals, pure and doped crystals were ground into powder and densely filled into the cells. A Qswitched Nd: YAG laser (DCR11) was used as a light source. A laser beam of fundamental wavelength $1064 \mathrm{~nm}, 8 \mathrm{~ns}$ pulse width, with $10 \mathrm{~Hz}$ pulse rate was made to fall normally on the sample cell. The power of the incident beam was measured using a power meter. The transmitted fundamental wave was passed over a monochromator (Czemy Turner monochromator), which separates $532 \mathrm{~nm}$ (second harmonic signal) from $1064 \mathrm{~nm}$, and absorbed by a $\mathrm{CuSO}_{4}$ solution, which removes the $1064 \mathrm{~nm}$ light, and passed through BG34 
filter to remove the residual $1064 \mathrm{~nm}$ light and an interference filter with bandwidth of $4 \mathrm{~nm}$ and central wavelength of $532 \mathrm{~nm}$. The green light was collected by a photomultiplier tube (Hamamatsu). The input laser energy incident on the powdered sample was $1.35 \mathrm{~mJ} / \mathrm{pulse}$. An emission of green light was seen in all the samples. It was observed that the measured SHG efficiency of L-alanine doped (5 mol\%) ADP was 1.75 and $\mathrm{LAHCl}$ doped (5 mol $\%$ ) ADP was 1.5 that of pure ADP.

\subsection{Piezoelectric measurements}

Piezoelectricity is the ability of certain crystals to generate an electric charge when subjected to mechanical stress. The piezoelectric property is related to the polarity of the material (Ge et al 2008). The piezoelectric studies were made using piezometer system. A precision force generator applied a calibrated force $(0.25 \mathrm{~N})$ which generated a charge on the piezoelectric material under test. An oscilloscope gives the output in $d_{33}$ coefficient in of $\mathrm{pC} / \mathrm{N}$ units. Piezoelectric measurements were conducted for the grown crystals by without polishing of the crystal. Pure ADP crystal gives the piezoelectric coefficient $\left(\mathrm{d}_{33}\right)$ value of $0.37 \mathrm{pC} / \mathrm{N}$. The obtained piezoelectric coefficient $\left(\mathrm{d}_{33}\right)$ values for $\mathrm{LAHCl}$ doped $(5 \mathrm{~mol} \%)$ ADP and L-alanine doped ( $5 \mathrm{~mol} \%$ ) ADP crystals are 0.68 and $0.8 \mathrm{pC} / \mathrm{N}$. Thus, $\mathrm{d}_{33}$ value of $5 \mathrm{~mol} \% \mathrm{LAHCl}$ doped ADP crystal is 1.84, while and for $5 \mathrm{~mol} \%$ L-alanine doped ADP crystal it is 2.16 times higher than that of pure ADP crystal. Greater crystalline perfection may be the reason for the increase in piezoelectric efficiency.

\section{Conclusions}

With the aim of improving the quality of ADP crystals with better optical properties for both academic and industrial uses, an attempt has been made in this present work to grow the ADP crystals by doping it with new additives L-arginine monohydrochloride and L-alanine. The addition of these amino acid materials enhances the metastable zone width and induction period of pure ADP solution. Also, during the experiment it was observed that the number of tiny crystals formed by spontaneous nucleation was appreciably reduced in the case of doped solution. It is believed that the addition of these amino acid materials suppresses the activities of the metal ion impurities present in the solution which enables larger metastable zone width and faster growth rate. HRXRD curves recorded for $5 \mathrm{~mol} \%$ doped crystals have excellent crystalline perfection. The FTIR spectrum shows that amino acid additives have entered into the ADP crystals. The transmission spectrum reveals that the crystal has sufficient transmission in the entire visible and IR region. The SHG conversion efficiency and piezoelectric coefficient values of doped crystals are higher than that of pure. This study will help the growth of high quality large size ADP single crystals.

\section{References}

Aithal, P. S., Nagaraja, H. S., Mohan Rao. P., Avasti, D. K. \& Sarma, A (1997). Effect of high energy ion irradiation on electrical and optical properties of organic nonlinear optical crystals, Vacuum, Vol. 48, (No. 12), pp. 991-994.

Alexandru, H. V. \& Antohe (2003). Prismatic faces of KDP crystal, kinetic and mechanism of growth from solutions, J. Cryst. Growth, Vol. 258, (No. 1-2), pp. 149-157. 
Asakuma, Y., Ukita, E., Maeda, K., Fukui, K., Iimura, K., Suzuki, M. \& Hirota, M (2007). Surface topography of dyed potassium dihydrogen phosphate (KDP) Crystals, Cryst. Growth Des., Vol. 7, (No. 2), pp. 420-424.

Batra, A. K., Stephens, J., Bhat, K., Aggarwal, M. D., Peterson, B. H., Curley, M. \& Lal, R. B. (2005). Investigation on the growth kinetics of KDP: LAP and TGS: LAP single crystals, Proc. of SPIE, Vol. 5912, pp. 591206-591212.

Batterman, B. W. \& Cole, H. (1964). Dynamical diffraction of X-rays by perfect crystals, Rev. Mod. Phys., Vol. 36, (No. 3), pp. 681-717.

Bhagavannarayana, G. (1994). High resolution X-ray diffraction study of as-grown and $B F_{2}{ }^{+}$ implanted silicon single crystals, Ph. D. Thesis, University of Delhi, Delhi, India.

Bonse, U. \& Hart, M. (1965). Tailless X-ray single crystal reflection curves obtained by multiple reflection, Appl. Phys. Lett., Vol. 7, (No. 9), pp. 238-240.

Boukhris, A., Souhassou, M., Lecomte, C., Wyneke, B. \& Thalal, A. (1998). Evolution of the structural and mean square displacement parameters in $\left(\mathrm{NH}_{4}\right)_{\times} \mathrm{K}_{1-\mathrm{x}} \mathrm{H}_{2} \mathrm{PO}_{4}$ solid solutions versus concentration and temperature, J. Phys.: Condens. Matter, Vol. 10, (No. 7), pp. 1621-1626.

Davey, R. J. \& Mullin, J. W. (1974). Growth of the $\{100\}$ faces of ammonium dihydrogen phosphate crystals in the presence of ionic species, J. Cryst. Growth, Vol. 26, (No. 1), pp. 45-51.

Dmitriev, V. G., Gurzadyan, G. G. \& Nikogosyan, D. N. (1991). Handbook of nonlinear optical crystals, Springer, Berlin.

Fu, Y-J., Gao, Z-S., Sun, X., Wang, S-L., Li, Y-P., Zeng, H., Luo, J-P., Duan, A-D. \& Wang, J-Y. (2000). Effects of anions on rapid growth and growth habit of KDP crystals, Prog. Cryst. Growth Charact., Vol. 40, (No. 1-4), pp. 211-220.

Ge, W., Liu, H., Zhao, X., Pan, X., He, T., Lin, D., Xu, H. \& Luo, H. (2008). Growth and characterization of $\mathrm{Na}_{0.5} \mathrm{Bi}_{0.5} \mathrm{TiO}_{3}-\mathrm{BaTiO}_{3}$ lead-free piezoelectric crystal by the TSSG method, J. Alloys and Compounds, Vol. 456, (No. 1-2), pp. 503-507.

Goma, S., Padma, C. M. \& Mahadevan, C. K. (2006). Dielectric parameters of KDP single crystals added with urea, Mater. Lett., Vol. 60, (No. 29-30), pp. 3701-3705.

Gunning, M. J., Raab, R. E. \& Kucharczyk, W. (2001). Magnitude and nature of the quadratic electro-optic effect in potassium dihydrogen phosphate and ammonium dihydrogen phosphate crystals, J. Opt. Soc. Am. B., Vol. 18, (No. 8), pp. 1092-1098.

Hewat, A. W. (1973). Location of hydrogen atoms in ADP by neutron powder profile refinement, Nature, Vol. 246, pp. 90-91.

Kern, R. \& Dassonville, R. (1992). Growth inhibitors and promoters exemplified on solution growth of paraffin crystals, J. Cryst. Growth, Vol. 116, (No. 1-2), pp. 191-203.

Kubota, N., Fukazawa, J., Yashiro, H. \& Mullin, J. W. (1995). Impurity effect of chromium (III) on the growth and dissolution rates of potassium sulfate crystals, J. Cryst. Growth, Vol. 149, (No. 1-2), pp. 113-119.

Kumaresan, P., Moorthy Babu, S. \& Anbarasan, P. M. (2008). Thermal, dielectric studies on pure and amino acid (L-glutamic acid, L-histidine, L-valine) doped KDP single crystals, Opt. Mater., Vol. 30, (No. 9), pp. 1361-1368.

Kurtz, S. K. \& Perry, T. T. (1968). A powder technique for the evaluation of nonlinear optical materials, J. Appl. Phys., Vol. 39, (No. 8), pp. 3798-3813. 
Lal, K. \& Bhagavannarayana, G. (1989). A high-resolution diffuse X-ray scattering study of defects in dislocation-free silicon crystals grown by the float-zone method and comparison with Czochralski-grown crystals, J. Appl. Cryst., Vol. 22, (No. 3), pp. 209-215.

Li, G., Liping, X., Su, G., Zhuang, X., Li, Z. \& He, Y. (2005). Study on the growth and characterization of KDP-type crystals, J. Cryst. Growth, Vol. 274, (No. 3-4), pp. 555562.

Matsushita, E. \& Matsubara, T. (1987). The role of hydrogen bonds in antiferroelectricity of $\mathrm{NH}_{4} \mathrm{H}_{2} \mathrm{PO}_{4}$, J. Phy. Soc. Jpn, Vol. 56, pp. 200-207.

Meena, M. \& Mahadevan, C. K. (2008). Growth and electrical characterization of L-arginine added KDP and ADP single crystals, Cryst. Res. Technol., Vol. 43, (No. 2), pp. 166172.

Meenakshisundaram, S., Parthiban, S., Madhurambal, G. \& Mojumdar, S. C. (2009). Effect of low and high concentrations of $\mathrm{KCl}$ dopant on ADP crystal properties, J. Therm. Anal. Calorimetry, Vol. 96, pp. 77-80.

Meera, K., Muralidharan, R., Tripathi, A. K. \& Ramasamy, P. (2004). Growth and characterisation of L-threonine, DL-threonine and L-methionine admixtured TGS crystals, J. Cryst. Growth, Vol. 263, (No. 1-4), pp. 524-531.

Monaco, S. B., Davis, L. E., Velso, S. P., Wang, F. T., Eimerl, D. \& Zalkin, A. (1987). Synthesis and characterization of chemical analogs of L-arginine phosphate, J. Cryst. Growth, Vol. 85, (No. 1-2), pp. 252-255.

Mullin, J. W. (1993). Crystallization, Butterworth-Heinemann, Oxford, London.

Nakatsuka, M., Fujioka, K., Kanabe, T. \& Fujita, H. (1997). Rapid growth over 50 mm/day of water-soluble KDP crystal, J. Cryst. Growth, Vol. 171, (No. 3-4), pp. 531-537.

Nyvlt, J., Rychly, R., Gottfried, J. \& Wurzelova, J. (1970). Metastable zone-width of some aqueous solutions, J. Cryst. Growth, Vol. 6, (No. 2), pp. 151-162.

Parikh, K. D., Dave, D. J., Parekh, B. B. \& Joshi, M. J. (2007). Thermal, FT-IR and SHG efficiency studies of L-arginine doped KDP crystals, Bull. Mater. Sci., Vol. 30, (No. 2), pp. 105-112.

Podder, J., Ramalingom, S. \& Kalkura, S. N. (2001). An investigation on the lattice distortion in urea and $\mathrm{KCl}$ doped KDP single crystals by X-ray diffraction studies, Cryst. Res. Technol., Vol. 36, (No. 6), pp. 549-556.

Podder, J. (2002). The study of impurities effect on the growth and nucleation kinetics of potassium dihydrogen phosphate, J. Cryst. Growth, Vol. 237-239, (No. 1), pp. 70-75.

Rajesh, N. P., Meera, K., Srinivasan, K., Santhana Raghavan, P. \& Ramasamy, P. (2000). Effect of EDTA on the metastable zone width of ADP, J. Cryst. Growth, Vol. 213, (No. 3-4), pp. 389-394.

Rajesh, P., Ramasamy, P. \& Bhagavannarayana, G. (2009). Effect of ammonium malate on growth rate, crystalline perfection, structural, optical, thermal, mechanical, dielectric and NLO behaviour of ammonium dihydrogen phosphate crystals, $J$. Cryst. Growth, Vol. 311, pp. 4069-4075.

Rak, M., Eremin, N. N., Eremina, T. A., Kzunetsov, V. A., Okhrimenko, T. M., Furmanova, N. G. \& Efremova, E. P. (2005). On the mechanism of impurity influence on growth kinetics and surface morphology of KDP crystals-I: defect centres formed by bivalent and trivalent impurity ions incorporated in KDP structure-theoretical study, J. Cryst. Growth, Vol. 273, (No. 3-4), pp. 577-585. 
Rani, T. J., Loretta, F., Selvarajan, P., Ramalingom, S. \& Perumal, S. (2011). Growth Structural and Spectral Studies on L-Proline Added Ammonium Dihydrogen Phosphate Single Crystals, Recent Research in Science and Technology, Vol. 3, (No. 7), pp. 69-72.

Razzetti, C., Ardoino, M., Zanotti, L., Zha, M. \& Paorici, C. (2002). Solution growth and characterisation of L-alanine single crystals, Cryst. Res. Technol., Vol. 37, (No. 2), pp. 456-465.

Ren, X., Xu, D. \& Xue, D. (2008). Crystal growth of KDP, ADP, and KADP, J. Cryst. Growth, Vol. 310, (No. 7-9), pp. 2005-2009.

Sangwal, K. (1989). On the estimation of surface entropy factor, interfacial tension, dissolution enthalpy and metastable zone-width for substances crystallizing from solution, J. Cryst. Growth, Vol. 97, (No. 2), pp. 393-405.

Sangwal, K. (1996). Effects of impurities on crystal growth processes, Prog. Cryst. Growth Charact., Vol. 32, (No. 1-3), pp. 3-43.

Shantha, K., Philip, S. \& Varma, K. B. R. (1997). Effect of KCl addition on the microstructural and dielectric properties of bismuth vanadate ceramics, Mater. Chem. Phys., Vol. 48, (No. 1), pp. 48-51.

Srinivasan, K. (1997). Growth of device quality KDP family single crystals, fabrication of nonlinear and electro-optical devices out of them and growth of ADP-KDP mixed crystals and their characterization, Ph. D. Thesis, Alagappa University, Karaikudi, India.

Srinivasan, K., Meera, K. \& Ramasamy, P. (1999). Enhancement of metastable zone width for solution growth of potassium acid phthalate, J. Cryst. Growth, Vol. 205, (No. 3), pp. 457-459.

Tenzer, L., Frazer, B. C. \& Pepinsky, R. (1958). A neutron structure analysis of tetragonal $\mathrm{NH}_{4}\left(\mathrm{H}_{2} \mathrm{PO}_{4}\right)$, Acta Crystallogr., Vol. 11, (No. 7), pp. 505-509.

Tukubo, H. \& Makita, H. (1989). Refractometric studies of $\mathrm{NH}_{4} \mathrm{H}_{2} \mathrm{PO}_{4}$ and $\mathrm{KH}_{2} \mathrm{PO}_{4}$ solution growth; experimental setup and refractive index data, J. Cryst. Growth, Vol. 94, (No. 2), pp. 469-474.

Ueda, R. (1948). Crystal structure of ammonium dihydrogen phosphate $\mathrm{NH}_{4} \mathrm{H}_{2} \mathrm{PO}_{4}$, J. Phys. Soc. Jpn., Vol.3, pp. 328-333.

Zaitseva, N. P., Rashkovich, L. N. \& Bogatyreva, S. V. (1995). Stability of $\mathrm{KH}_{2} \mathrm{PO}_{4}$ and $\mathrm{K}\left(\mathrm{H}_{2} \mathrm{D}\right)_{2} \mathrm{PO}_{4}$ solutions at fast crystal growth rates, J. Cryst. Growth, Vol. 148, (No. 3), pp. 276-282.

Zaitseva, N. \& Carman, L (2001). Rapid growth of KDP-type crystals, Prog. Cryst. Growth Charact., Vol. 43, (No. 1), pp. 1-118. 


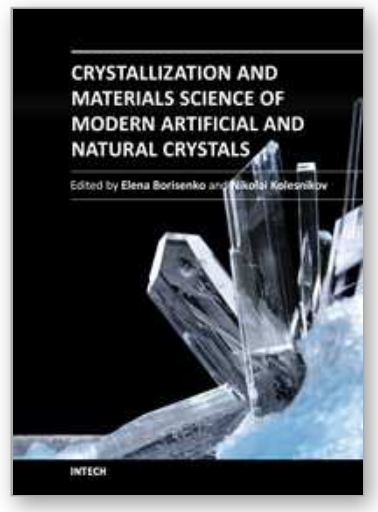

\section{Crystallization and Materials Science of Modern Artificial and Natural Crystals}

Edited by Dr. Elena Borisenko

ISBN 978-953-307-608-9

Hard cover, 328 pages

Publisher InTech

Published online 20, January, 2012

Published in print edition January, 2012

Crystal growth is an important process, which forms the basis for a wide variety of natural phenomena and engineering developments. This book provides a unique opportunity for a reader to gain knowledge about various aspects of crystal growth from advanced inorganic materials to inorganic/organic composites, it unravels some problems of molecular crystallizations and shows advances in growth of pharmaceutical crystals, it tells about biomineralization of mollusks and cryoprotection of living cells, it gives a chance to learn about statistics of chiral asymmetry in crystal structure.

\section{How to reference}

In order to correctly reference this scholarly work, feel free to copy and paste the following:

P.V. Dhanaraj and N.P. Rajesh (2012). Effect of Amino Acid Additives on Crystal Growth Parameters and Properties of Ammonium Dihydrogen Phosphate Crystals, Crystallization and Materials Science of Modern Artificial and Natural Crystals, Dr. Elena Borisenko (Ed.), ISBN: 978-953-307-608-9, InTech, Available from: http://www.intechopen.com/books/crystallization-and-materials-science-of-modern-artificial-and-naturalcrystals/effect-of-amino-acid-additives-on-crystal-growth-parameters-and-properties-of-ammoniumdihydrogen-ph

\section{INTECH}

open science | open minds

\section{InTech Europe}

University Campus STeP Ri

Slavka Krautzeka 83/A

51000 Rijeka, Croatia

Phone: +385 (51) 770447

Fax: +385 (51) 686166

www.intechopen.com

\section{InTech China}

Unit 405, Office Block, Hotel Equatorial Shanghai

No.65, Yan An Road (West), Shanghai, 200040, China

中国上海市延安西路65号上海国际贵都大饭店办公楼 405 单元

Phone: +86-21-62489820

Fax: +86-21-62489821 
(C) 2012 The Author(s). Licensee IntechOpen. This is an open access article distributed under the terms of the Creative Commons Attribution 3.0 License, which permits unrestricted use, distribution, and reproduction in any medium, provided the original work is properly cited. 